\title{
The Research on the Construction of Undergraduate Teaching Quality in Employability-oriented
}

\author{
Gulimire·Agemaiti, Y.SHI (Corresponding author) \\ College of Engineering and Technology, Tianjin Agriculture University, Tianjin, China
}

\author{
Y.WANG, H.R JIN \\ Student Center for Innovation and Entrepreneurship, Tianjin Agriculture University, Tianjin, China
}

\begin{abstract}
Employability of college students is that they obtained through learning and practice in school which can achieve ideal job and meet the needs of society, so as to realize their own value. Besides that it is the basis and premise of the role conversion from the students to the employees. Therefore, universities should set up specialized courses to meet the needs of the job market and enterprises, efforts to enhance the quality of teaching, cultivate students' practical ability, professional competence, innovation ability and comprehensive quality, in order to improve the quality of graduates majored in engineering. Create a favorable environment conducive to the employment of university graduates, finally encourage university graduates to realize own life value and better serve the society.
\end{abstract}

KEYWORD: Employability; Teaching Quality; Capacity Factors; System Design

\section{INTRODUCTION}

In recent years, the number of college graduates has increased in our country year after year. According to statistics, China has reached 6.99 million college graduates in 2013, known as the "season" in the history of the most difficult employment. And on this basis, the data still grow in 2014, which is expected to exceed 7 million. This year turns into a "more difficult to obtain employment season". Face to such a large crowd of university graduates, how to improve their employability which makes graduates more in line with business needs become a difficult problem in front of colleges and universities[1].

The ministry of education pointed out that "Improve quality is the core task of higher education development, the basic requirement to construct powerful higher education ". Graduates are "products" of the school. The way out of the graduates good or bad fundamentally depends on the quality of teaching.

2 THE ANALYSIS ON DIFFERENCES BETWEEN THE STUDENTS' PRACTICAL SKILLS AND THE EXPECTATION OF ENTERPRISES

\subsection{Preparing the new file with the correct template}

Colleges and enterprises are respectively the supplier and the buyer in the labor market. If talents colleges and universities cultivated and market demand does not match, the supply and demand of the quality of labor will be disjointed[1]. In order to accurately analyze the differences between practical skills of college graduates and market demand, this paper uses methods such as questionnaire investigation, discussion and individual visits, which has chose more than 50 employers in Tianjin and Beijing area, graduates major in agricultural mechanization and automation and measurement and control technology and instrumentation who have graduated within three years as the research objects. Investigate the employers' basic requirements of quality and ability of graduates, differences of skills between supply and demand sides in job market and main reason of influence on students' employability in detail.

According to the data analysis, obtain the abilities of graduates the enterprise needs, as shown in Figure1.

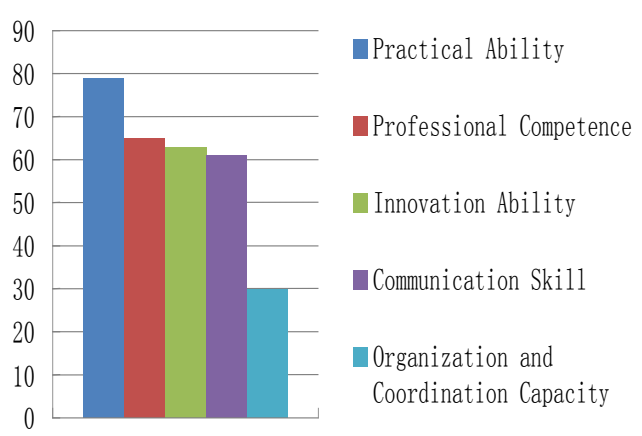

Figure 1. Capacity factors graduates need to have. 
The Figure 1 shows that the ability requirements of the engineering graduates which employers need mainly focused on practical ability, professional competence, innovation ability and communication skill. The ability of undergraduate needed more urgently shows that there are differences between practical skills of graduates and market demand. Mainly reflected in difficult employment, it is difficult to find a satisfactory job, while most of the employers could not find the graduates with strong practical ability and high comprehensive quality. In other words, the graduates cannot find a suitable job while the enterprises cannot find a suitable talent"[1]. The employability of graduates contains ability of hunting for jobs, practical ability, professional competence and adaptability. The construction of undergraduate teaching quality in employabilityoriented with the aim to improve the quality of personnel training of university is a reasonable and necessary educational measures which can meet the demand for talent, reflect the development trend and needs of modern education.

\section{BUILD TEACHING QUALITY ASSURANCE SYSTEM BASED ON IMPROVING STUDENTS' EMPLOYABILITY}

\subsection{Build Curriculum System in Employability- oriented}

In terms of professional curriculum system, it is a structural state with combination of multiple curriculums, which obeys and serves the specialized talents training. From the perspective of system theory, the curriculum system of engineering also has obvious system characteristics, such as purpose, integrity, hierarchy and correlation. College of engineering and technology of Tianjin Agriculture University has three majors including agricultural mechanization and automation, measurement and control technology and instrument and new energy science and engineering. By the means of the ideas of Gen-nian Sun and Rong Zhao on curriculum system optimization[2-3], this article gives the curriculum system of engineering under the system thinking reflected "wide base, extensive knowledge, strong ability and high quality" (as shown in Figure2).

Teaching contents and curriculum system are the key to guarantee the quality of teaching. Design curriculum to improve students' comprehensive ability through the training of basic theory, practice, innovative design, scientific research, cooperation and communication and so on. At the same time, the universities also should adjust the professional curriculum setting and teaching plan according to enterprise's demand, narrowing the gap between practical skills of college graduates and enterprises expected skills, in order to meet the ability requirements of the enterprises for graduates, as shown in Figure 3.

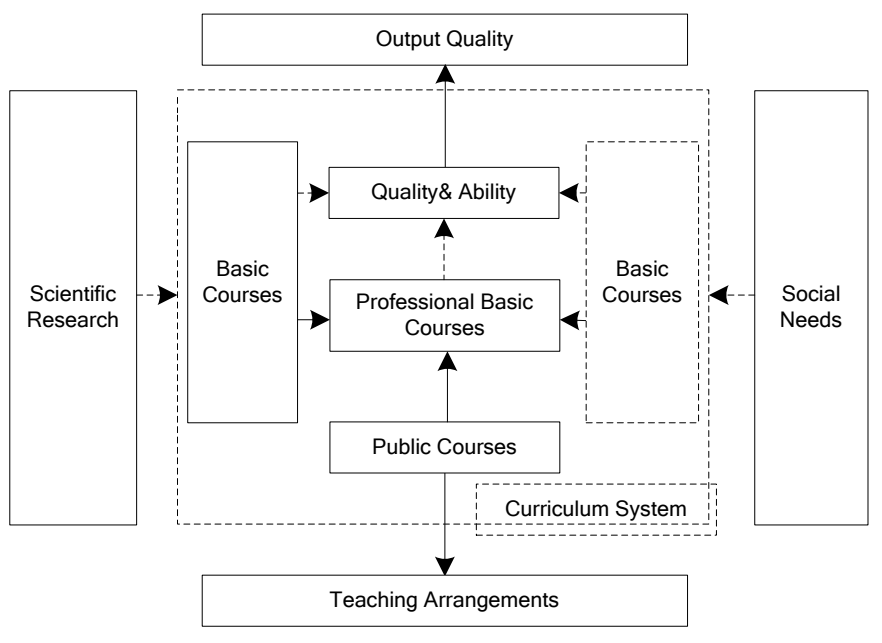

Figure 2. Curriculum system of engineering.

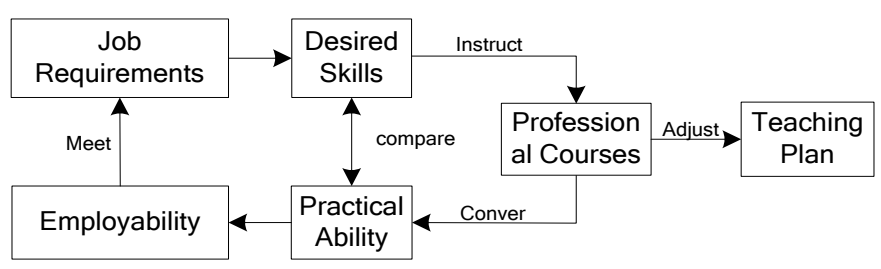

Figure 3. Curriculum system in employability-oriented.

Combining with the professional characteristics of college of engineering and technology involved, the construction of curriculum system mainly includes: classroom teaching (basic courses + professional basic courses + public courses), innovative quality training (internship base + innovation center + course design) and the ability to expand (race + scientific research activities). The classroom teaching includes "basic course" which consists of moral lesson, math, science, English, computer, sports, and other courses; "specialized courses" which consists of professional basic courses and professional elective course module, which have the characteristics of basic, comprehensive and small minority. Professional elective course module is divided into professional direction module, knowledge structure module and ability structure module, in order to provide a freedom of choice within the scope prescribed by the teaching plan for students. "Public elective courses" includes cultural quality of elective courses, professional development elective courses and enhance elective courses. The courses mainly applied, aiming to broaden students' knowledge and improving the comprehensive quality. Visit to the enterprises in the form of periodic survey in order to obtain information feedback, and then adjust the teaching contents of professional courses module and quality development module, with survey cycles for two years. 


\subsection{Build a New Practical Teaching System}

Practical teaching is important with a strategic position in the undergraduate course system, which is a platform of linking theory with practice, imparting professional knowledge and improving the employment ability. The quality of practical teaching directly decides the pros and cons of running a school. The structure of the practical teaching content should follow the idea from shallower to deeper and from basic to comprehensive.

Combine with the educational philosophy and characteristics of engineering professions of Tianjin Agriculture University, benefit from the "three tier architecture" system in programming[4], in order to build a new practical teaching system in employability-oriented, as shown in Figure 4.
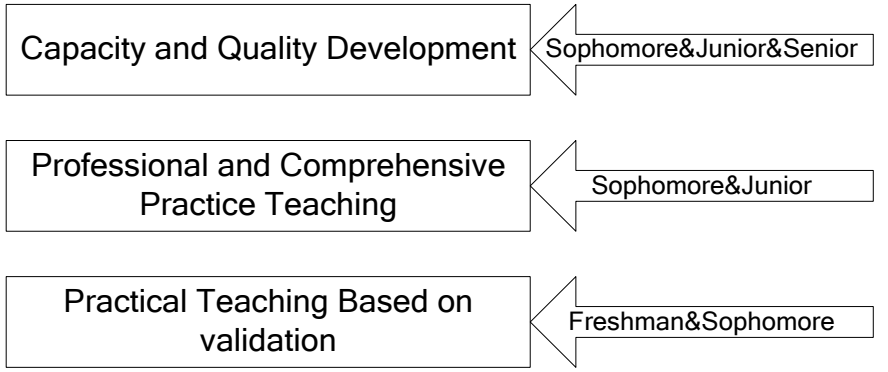

Figure 4. Three tier architecture system for Practical teaching

The first level, practical teaching based on foundational validation, it mainly includes experiments and foundational practice for single course. For a freshman and sophomore, validation experiments should be achieved by group discussion, which could build the mode of exploratory research learning under the guidance of teachers. With the aid of the discussion courses, students will be able to adapt to the learning environment in university as soon as possible, learn the basic methods of scientific research, and cultivate the exploration spirit and criticism spirit. At the same time, create an opportunity of inquiry learning under the cooperative environment for students, stimulate students' interest in exploring the unknown world, and exercise the ability to communicate and express, and then guide students' autonomous learning.

The second level, practical teaching is professional and comprehensive which mainly includes cognition practice, course design, production practice and professional integrated design. This process is a practice which aimed to establish a perceptual cognition for students on a certain stage or a training system which aimed to analyze and solve problems through comprehensive knowledge learnt. Guide students to establish the learning goals and examine the depth and breadth of professional knowledge learnt. Finally, cultivate students' comprehensive ability to solve the problem using knowledge.
The third level, ability and quality development which mainly include the student research training program, innovative design experiments and extracurricular science and technology competitions. Under the guidance of teachers, conduct the preliminary scientific research activities taking students as main body. Implement a gradient cultivation mechanism as "the basic research training - research ability enhancement - innovative thinking guidance". Through the actual research and projects, cultivate the scientific research consciousness, cooperation spirit and innovation ability for students, which could inspire the courage and interest of students to learn theoretical knowledge and explore the unknown. To the senior, we will strictly control the quality standard of graduation thesis and establish academic integrity management approach of graduation thesis.

The three tier architecture system for practical teaching, which can penetrate the practical teaching into learning behavior during four years, realize the scientificity and continuity of practice in personnel training level.

The new practical teaching system is established on the basis of transporting available talent to the enterprise, therefore, the university should explore and establish an operation mechanism with the enterprise to cultivate talents and actively promote the collaborative innovation. Enterprises have excellent engineering practice environment, advanced technology, scientific management, and excellent enterprise culture, which are the high quality education resources. They form the complementary advantages with college education resources. Through the strategic cooperation with enterprises, the university could introduce highquality engineering education resources in industry and establish the personnel training platform including teaching, scientific research, production and training.

\section{MONITORING AND INFORMATION FEEDBACK FOR QUALITY OF TEACHING}

From the level of cultivation results which reflect the students' employment ability, college teaching quality assurance achieves as a cycle, as "to establish the teaching quality goal-to analyze the control status of teaching quality-to find out problems and deficiencies-to raise and implement improvement measures-to achieve the goals of teaching quality" [5]. Academic, administrative and supervisory coordination with each other, play teaching quality monitoring and management functions. The analysis on the students' academic situation, the employment ability and tracking surveys who continued their studies, whose results could evaluate the quality of personnel training and the social needs, for talents 
training mode. It can provide personnel training, curriculum setting and teaching management with diagnosis, which can promote the quality of teaching.

\section{CONCLUSIONS}

Higher education is not only to ensure the quality of personnel training traditionally, and also ensure them to meet the new requirements of the international competitive power in the information age and the background to create an innovative country. To ensure and improve the teaching quality of education, to build personnel transport mechanism to meet the demand of the labor market, to improve and enhance the students' professional knowledge, practical ability and comprehensive quality, to create a favorable environment conducive to the employment of university graduates, finally encourage university graduates to realize own life value and better serve the society.

\section{ACKNOWLEDGMENT}

The research of this paper was supported by Training Programs of Innovation and Entrepreneurship for Undergraduates (201410061033) and Science Development Funds of Tianjin Agricultural University (2013S06).

\section{REFERENCES}

[1] Yanhui Lu, "Employment ability oriented to construct the meaning of practical teaching system in colleges and universities and the way." Work and Abroad, 14, 2011, pp. 13-14.

[2] Gen-nian Sun, "On the systematic view and method of the courses structure optimization," Journal of Higher Education, Vol.22(2), 2000, pp. 86-90.

[3] Rong Zhao, Peng Zou, and Yabing Cha, Army military comprehensive university curriculum system optimization of system theory and method system, Journal of Higher Education Research, Vol.26(4), 2003, pp. 74-76.

[4] Dino Esposito, Andrea Saltarello, "Microsoft .NET Architecting Applications for the Enterprise," Microsoft Press, 2008, pp. 211-234.

[5] Wengui Chen, Research and Practice on Inner Teaching Quality Guarantee System in Universities and Colleges, Tianjin University, 2005, pp. 12-14. 